\title{
Etiology of end-stage renal disease amongst hemodialysis patients in Makkah city, Saudi Arabia
}

\author{
Alaa H. Qadhi ${ }^{1}$, Khloud J. Ghafouri ${ }^{1}$, Wedad F. Azhar ${ }^{1}$, Doaa R. Negm ${ }^{1}$, Firas S. Azzeh ${ }^{1}, *$, Alkhateeb K. Alkemary ${ }^{2}$ \\ ${ }_{1}^{1}$ Department of Clinical Nutrition, Faculty of Applied Medical Sciences, Umm Al-Qura University, Makkah, Saudi Arabia \\ ${ }^{2}$ Department of Internal Medicine (Internal Medicine and Nephrology), Faculty of Medicine, Cairo University, Cairo, Egypt
}

\section{A R T I C L E IN F O}

\section{Article history:}

Received 28 November 2020

Received in revised form

13 February 2021

Accepted 13 February 2021

\section{Keywords:}

End-stage renal disease

Etiology

Makkah

\begin{abstract}
A B S T R A C T
In recent years, the number of hemodialysis (HD) patients has increased in the Kingdom of Saudi Arabia. End-stage renal disease (ESRD) is associated with increased rates of hospital admission, morbidity, and mortality. Globally, the most common causes of ESRD are diabetic nephropathy, hypertension, glomerulonephritis, infections, and chronic obstruction. However, very limited data have been presented regarding the etiology of ESRD in Saudi Arabia, especially in Makkah City. Therefore, this crosssectional study is designed to determine the underlying etiologies of ESRD in hemodialysis patients. The study was conducted among 306 patients who were recruited from Makkah hospitals and HD centers. The obtained data showed that diabetes was the most common cause of ESRD (34.3\%), followed by hypertension (20.9\%), drug misuse (12.1\%), hereditary conditions $(10.1 \%)$, urinary tract obstruction, and urinary retention $(9.8 \%)$, unknown reason (8.2\%), and chronic inflammation of the kidneys (3.3\%). In conclusion, this study highlights the most important factors contributing to ESRD in the Makkah region. Thus, national campaigns should be performed to increase awareness about these factors and to possibly reduce the incidence of the disease.
\end{abstract}

(C) 2021 The Authors. Published by IASE. This is an open access article under the CC BY-NC-ND license (http://creativecommons.org/licenses/by-nc-nd/4.0/).

\section{Introduction}

End-stage renal disease (ESRD) has become an increasing public health issue in both high- and middle-income countries. Even in developed nations, ESRD is the main fee driver of healthcare systems (Couser et al., 2011). Chronic kidney disease (CKD) is a condition associated with increased rates of hospital admission, morbidity, and mortality (Mathur et al., 2010; Kerr et al., 2012). In 2016, figures from the United States Renal Data System indicated that there were approximately 370 new cases per million people (PMP) annually in the USA (Saran et al., 2016). In Saudi Arabia, the incidence and prevalence of ESRD have risen in the last three decades and exceed those found in European and American populations. This increase is a result of large-scale urbanization, rapid lifestyle changes, and excessive population growth. Additionally, $2.21 \%$ of

\footnotetext{
* Corresponding Author.

Email Address: fsazzeh@uqu.edu.sa (F. S. Azzeh)

https://doi.org/10.21833/ijaas.2021.06.002

(1) Corresponding author's ORCID profile:

https://orcid.org/0000-0002-1400-5465

2313-626X/@ 2021 The Authors. Published by IASE.

This is an open access article under the CC BY-NC-ND license

(http://creativecommons.org/licenses/by-nc-nd/4.0/)
}

annual deaths occur as a result of CKD patients who progress to ESRD (Al-Sayyari and Shaheen, 2011).

The understanding of the etiology of ESRD in the Kingdom of Saudi Arabia (KSA), especially in Makkah, is limited. Therefore, this study aims to determine the etiology factors leading to ESRD in hemodialysis (HD) patients in Makkah City, Saudi Arabia.

\section{Subjects and methods}

\subsection{Subjects}

This cross-sectional study appraised 306 patients from the in-patient wards of King Faisal Hospital, AlNoor Specialist Hospital, and from the HD centers in Makkah, including Diaverum and Al-Jamiyyah AlKhairiyyah. The study was conducted from November 2019 to January 2020. All adult HD patients from the hospitals and centers in Makkah were included. We excluded any patients younger than 18 years and who live outside Makkah City.

\subsection{Methods}

All patients were on regular HD and gave written consent. Data were collected from patient's medical 
records and were confirmed through standardized questionnaire-based (Almutairi et al., 2017) interviews with patients. The information acquired was focused on patients' demographic characteristics, family history, and factors associated with ESRD.

\subsection{Statistical analyses}

The obtained data were statistically analyzed using IBM SPSS Statistics for Windows, version 20. Statistical significance was defined by using the chisquare test at $\mathrm{p} \leq 0.05$ for categorical variables.

\section{Results}

Table 1 shows the socio-demographic data of the patient cohort. The number of female and male patients who received HD were 193 and 113, respectively. Around $90.2 \%$ of the patients were Saudi. Most HD patients were in the age categories 45-61 years (43.1\%) and 35-44 years (21.6\%), followed by those over 61 years old (20.9\%). The mean age of the study population was $46 \pm 7.7$ years. The lowest age was 18 years old and the highest was 86 years old. The lowest percentage of patients was in the younger age group, i.e. between 18 and 24 years $(3.6 \%)$.

Most patients were married (65.7\%), followed by those who were widowed (14.7\%), and single $(8.2 \%)$. Few patients had postgraduate degrees $(0.3 \%)$; a small group had earned diploma-level educations (4.2\%). About $58.5 \%$ of the patients were unemployed, and $16.8 \%$ were employed; the least represented group was the student group (1.9\%). About $37.5 \%$ of the patients earned $<5000$ SAR/month, $\quad 26.1 \%$ earned 10000-20000 SAR/month, whilst only $10.9 \%$ of patients had an income $>20000 \mathrm{SAR} /$ month. No difference was seen in mean body mass index (BMI) values between male and female patients ( $27 \pm 1.1$ vs $27.6 \pm 1$, respectively).

Table 2 represents the causes of ESRF identified in this patient cohort. These were significantly different $(\mathrm{p}<0.05)$ between them. The most common underlying etiology reported was diabetes (34.3\%), followed by hypertension (20.9\%); ESRD related to unknown causes was found in $8.2 \%$.

Table 1: Frequency distribution of subjects according to their socio-demographic data

\begin{tabular}{|c|c|c|c|}
\hline \multicolumn{2}{|c|}{ Variables } & \multirow{2}{*}{$\begin{array}{c}\text { Frequency } \\
193\end{array}$} & \multirow{2}{*}{$\frac{\text { Percent }}{63.1}$} \\
\hline \multirow{3}{*}{ Gender } & Male & & \\
\hline & Female & 113 & 36.9 \\
\hline & Total & 306 & 100.0 \\
\hline \multirow{3}{*}{ Nationality } & Saudi & 276 & 90.2 \\
\hline & Non-Saudi & 30 & 9.8 \\
\hline & Total & 306 & 100.0 \\
\hline \multirow{6}{*}{$\begin{array}{l}\text { Age-group } \\
\text { (years) }\end{array}$} & $18-24$ & 11 & 3.6 \\
\hline & $25-34$ & 33 & 10.8 \\
\hline & $35-44$ & 66 & 21.6 \\
\hline & $45-61$ & 132 & 43.1 \\
\hline & Over 61 & 64 & 20.9 \\
\hline & Total & 306 & 100.0 \\
\hline \multirow{5}{*}{ Social status } & Married & 201 & 65.7 \\
\hline & Single & 25 & 8.2 \\
\hline & Widowed & 45 & 14.7 \\
\hline & Divorced & 35 & 11.4 \\
\hline & Total & 306 & 100.0 \\
\hline \multirow{8}{*}{ Educational level } & No schooling & 63 & 20.6 \\
\hline & Primary school & 52 & 17.0 \\
\hline & Middle School & 43 & 14.1 \\
\hline & High School & 83 & 27.1 \\
\hline & Diploma & 13 & 4.2 \\
\hline & $\begin{array}{c}\text { Bachelor's } \\
\text { degree }\end{array}$ & 51 & 16.7 \\
\hline & $\begin{array}{c}\text { Postgraduate } \\
\text { degree }\end{array}$ & 1 & 0.3 \\
\hline & Total & 306 & 100.0 \\
\hline \multirow{5}{*}{ Occupation } & Student & 6 & 1.9 \\
\hline & Employed & 51 & 16.8 \\
\hline & Retired & 70 & 22.8 \\
\hline & Unemployed & 179 & 58.5 \\
\hline & Total & 306 & 100.0 \\
\hline \multirow{5}{*}{$\begin{array}{l}\text { Income level } \\
\text { (SAR)/month }\end{array}$} & Less than 5000 & 86 & 37.5 \\
\hline & $5000-10000$ & 78 & 25.5 \\
\hline & $10000-20000$ & 80 & 26.1 \\
\hline & More than 20000 & 62 & 10.9 \\
\hline & Total & 306 & 100.0 \\
\hline
\end{tabular}

Other etiological factors could be related to drug misuse (12.1\%), hereditary conditions (10.1\%), urinary tract obstruction and urinary retention $(9.8 \%)$, and chronic inflammation of the kidneys $(3.3 \%)$.

Table 2: Frequency distribution of subjects according to ESRF etiology

\begin{tabular}{|c|c|c|c|c|}
\hline & Variables & Frequency & Percent & p-value \\
\hline \multirow{9}{*}{ Etiology of ESRD } & Urinary tract obstruction and urinary retention & 30 & 9.8 & \multirow{9}{*}{$\mathrm{P}<0.05$} \\
\hline & Drug misuse (antibiotics/analgesics) & 37 & 12.1 & \\
\hline & Chronic inflammation of the kidneys & 10 & 3.3 & \\
\hline & Diabetes & 105 & 34.3 & \\
\hline & Hypertension & 64 & 20.9 & \\
\hline & Hereditary conditions & 31 & 10.1 & \\
\hline & Others & 4 & 1.3 & \\
\hline & Unknown & 25 & 8.2 & \\
\hline & Total & 306 & 100.0 & \\
\hline
\end{tabular}

Table 3 demonstrates that the etiology of ESRD was significantly different between male and female patients $(\mathrm{p}<0.05)$. The most common causes of ESRD in male patients were diabetes (31.1\%), hypertension $(22.3 \%)$, impaired kidney function from drug misuse, e.g., antibiotics or analgesics (14.5\%), and urinary tract obstruction and urinary retention $(10.4 \%)$. On the other hand, the majority of cases of ESRD in female patients were caused by diabetes (39.8\%), hypertension (18.6\%), and hereditary conditions (15\%).

\section{Discussion}

ESRD is characterized by progressive and irreversible impairment of renal function. Awareness of the cause of CRF helps the nephrologists to anticipate problems during renal 
Table 3: Etiology of ESRD according to gender

\begin{tabular}{|c|c|c|c|c|c|c|}
\hline \multirow{3}{*}{ Etiology of ESRD } & \multicolumn{4}{|c|}{ Gender } & \multirow{3}{*}{ Total } & \multirow{3}{*}{ p-value } \\
\hline & \multicolumn{2}{|c|}{ Male } & \multicolumn{2}{|c|}{ Female } & & \\
\hline & No. & $\%$ & No. & $\%$ & & \\
\hline Urinary tract obstruction and urinary retention & 20 & 10.4 & 10 & 8.9 & 30 & \\
\hline Drug misuse (antibiotics/analgesics) & 28 & 14.5 & 9 & 8 & 37 & \\
\hline Chronic inflammation of the kidneys & 10 & 5.2 & 0 & 0 & 10 & \\
\hline Diabetes & 60 & 31.1 & 45 & 39.8 & 105 & \\
\hline Hypertension & 43 & 22.3 & 21 & 18.6 & 64 & $\mathrm{P}<0.05$ \\
\hline Hereditary conditions & 14 & 7.3 & 17 & 15 & 31 & \\
\hline Others & 1 & 0.5 & 3 & 2.7 & 4 & \\
\hline Unknown & 17 & 8.8 & 8 & 7.1 & 25 & \\
\hline Total & 193 & 100 & 113 & 100 & 306 & \\
\hline
\end{tabular}

The incidence of ESRD in the U.S in 2017 was 340.7 PMP with 124,500 new cases registered. The prevalence of ESRD continues to rise and reached 746,557 in 2017 (versus 727,912 in 2016). The total Medicare spending on both CKD and ESRD patients was in excess of 120 billion US dollars in 2017. For identified CKD (not ESRD), the total Medicare expenditure was 84 billion US dollars. Spending for ESRD patients totaled 35.9 billion US dollars, accounting for $7.2 \%$ of the overall Medicare-paid claims (Saran et al., 2020). This reflects how much ESRD is an economic burden and the need to prevent it.

The dialysis statistics prepared by the Saudi Centre for Organ Transplantation (SCOT) at the end of 2016 showed a total of 17,687 dialysis patients, 16,315 of them are treated by HD, and the remaining 1,372 by peritoneal dialysis. The prevalence of endstage renal failure treated by dialysis is estimated to be 557 cases/PMP, total death was 1,769 (10\%), while the incidence of treated ESRD is estimated at 145 cases/PMP (SCOT, 2018).

Our study was conducted in Makkah; the holy city for all Muslims located in the Western region of KSA, where the prevalence of end-stage renal failure treated by dialysis is estimated to be 585 cases/PMP, while the incidence of treated ESRD is estimated as 146 cases/PMP (SCOT, 2018). Our study showed that the prevalence of treated ESRD in male patientswas almost twice that of females (6.1\% vs $36.9 \%$; Table 1). This male predominance among the ESRD population, is a poorly explained global phenomenon, with males constituting $58 \%$ in the US (NIH, 2020), 62.9\% in the UK (Byrne et al., 2018), and $56 \%$ in the KSA (SCOT, 2018). This study showed that the largest group of patients were in the age group 45-61 years (42.2\%), and the secondlargest group was aged over 61 years (26\%). About $80 \%$ were of Saudi nationality and $20 \%$ were nonSaudi. These distributions were similar to those in a study of ESRD patients in the city of Tabuk in Saudi Arabia where the highest percentage of the patients were in the age group 40-59 years (40.11\%), and the second-highest percentage were aged 60-79 years (27.79\%); $84.2 \%$ of patients were Saudi and $15.8 \%$ were non-Saudi (Almutairi et al., 2017).

Diabetic nephropathy (DN) is the commonest cause of ESRD in our patients (34.3\%), this is in agreement with 2016 SCOT data with DN responsible for $40 \%$ of cases (SCOT, 2018) and many other studies showing DN as the leading cause of ESRD accounting for $50 \%$ of cases in the developed world (Tuttle et al., 2014), and many Arabic countries such as Libya (Goleg et al., 2014), Kuwait, Egypt, and Lebanon (Shaheen and Al-Khader, 2005). Reflecting that DN became an important public health problem due to changes in dietary habits and lifestyle mandating prevention and early detection and management. Hypertension was responsible for $20.9 \%$ of all cases in our ESRD patients, compared with $38 \%$ in the whole country (SCOT, 2018). Hypertension is highly prevalent in Saudi Arabia. It was reported that hypertension affected more than $25 \%$ of the adult Saudi population (Saeed et al., 2011). This high prevalence may be related to the dietary and lifestyle changes of the Saudis (Almutary et al., 2013). In the US, hypertension and diabetes are the two leading causes for an increasing number of individuals with ESRD (NIH, 2020). Hypertension is also a major cause of ESRD in other regional countries such as Egypt (El-Minshawy and Kamel, 2011), Iran (Nemati et al., 2008), Sudan (El-Amin et al., 2010), and Turkey (Sengul et al., 2013).

ESRD as a complication of medications intake as analgesics represents $12.1 \%$ of our patients compared to 5\% in Tabuk (El-Minshawy et al., 2014) followed by hereditary causes and obstructive uropathy (9.8\%) each. This denotes the importance of the wise use of medications under medical supervision. Glomerulonephritis was seen in 3.3\% of our patients compared to $8.9 \%$ in Tabuk (Almutairi et al., 2017) and $9.6 \%$ in the US (NIH, 2020).

Our results showed that $8.2 \%$ of patients were with unknown causes of ESRD, but it was higher up to $10.5 \%$ in the Netherlands (ERA-EDTA, 2018), and $16.1 \%$ in the UK (ERA-EDTA, 2018); and much higher in developing countries whereas, in Yemen, there were more than $57 \%$ of patients with unknown cause of ESRD (Al-Rohani, 2003), and in Sudan more than $40 \%$ (El-Amin et al., 2010). This highlights the importance of medical services availability for early detection and management of possible causes and prevention of ESRD.

\section{Conclusion}

In conclusion, the study suggests that the etiology of ESRD amongst HD patients in Makkah City is 
related to diabetes, hypertension, drug misuse, hereditary conditions, urinary tract obstruction, and urinary retention, unknown reason, and chronic inflammation of the kidneys. However, urbanization and rapid lifestyle changes increased the incidence of DN and hypertension as the leading causes of ESRD in KSA and a national program to control both is mandatory, but at the same time the unknown causes are decreasing due to the improvement of investigational facilities and increasing awareness of ESRD risk factors and we recommend a wide-scale screening of the relatives of patients with ESRD for early detection and management of risk factors of ESRD.

\section{Acknowledgment}

The authors thank the registered dietitians in the hospitals and HD centers in Makkah for their help and support.

\section{Compliance with ethical standards}

\section{Ethical considerations}

Informed written consent was obtained from each patient, and all patient details were kept confidential under the current legal framework. This study was approved by the ethics and research committees of the Ministry of Health of the KSA (Approval number H-02-K-076-0619-122).

\section{Conflict of interest}

The author(s) declared no potential conflicts of interest with respect to the research, authorship, and/or publication of this article.

\section{References}

Almutairi FM, Al-Duais MA, Shalaby KA, and Sakran MI (2017). Analysis of patients with end-stage renal disease on dialysis in Tabuk City, Saudi Arabia: A single-center, three-year retrospective study. Saudi Journal of Kidney Diseases and Transplantation, 28(2): 349-354.

https://doi.org/10.4103/1319-2442.202769

PMid:28352019

Almutary HH, Bonner A, and Douglas C (2013). Chronic kidney disease in Saudi Arabia: A nursing perspective. Middle East Journal of Nursing, 101(900): 1-9.

Al-Rohani M (2003). Causes of chronic renal failure at one center in Yemen. Saudi Journal of Kidney Diseases and Transplantation, 14(1): 80-83.

Al-Sayyari AA and Shaheen FA (2011). End stage chronic kidney disease in Saudi Arabia. Saudi Medical Journal, 32(4): 339346.

Byrne C, Caskey F, Castledine C, Davenport A, Dawnay A, Fraser S, Maxwell H, Medcalf JF, Wilkie M, and Williams AJ (2018). 20 $0^{\text {th }}$ annual report of the renal association. UK Renal Registry, Bristol, UK.

Castro MC, Luders C, Elias RM, Abensur H, and Romão Junior JE (2006). High-efficiency short daily haemodialysis-Morbidity and mortality rate in a long-term study. Nephrology Dialysis Transplantation, 21(8): 2232-2238. https://doi.org/10.1093/ndt/gfl171 PMid:16632557
Couser WG, Remuzzi G, Mendis S, and Tonelli M (2011). The contribution of chronic kidney disease to the global burden of major noncommunicable diseases. Kidney International, 80(12): 1258-1270.

https://doi.org/10.1038/ki.2011.368 PMid:21993585

El Minshawy O, Ghabrah T, and El Bassuoni E (2014). End-stage renal disease in Tabuk Area, Saudi Arabia: An epidemiological study. Saudi Journal of Kidney Diseases and Transplantation, 25(1): 192-195.

https://doi.org/10.4103/1319-2442.124574

PMid:24434411

El-Amin S, Obeid W, and Abu-Aisha H (2010). Renal replacement therapy in Sudan, 2009. Arab Journal of Nephrology and Transplantation, 3(2): 31-36. https://doi.org/10.4314/ajnt.v3i2.58903

El-Minshawy 0 and Kamel EG (2011). Diabetics on hemodialysis in El-Minia Governorate, Upper Egypt: Five-year study. International Urology and Nephrology, 43(2): 507-512. https://doi.org/10.1007/s11255-010-9713-z PMid:20213293

ERA-EDTA (2018). ERA-EDTA registry annual report 2016. The European Renal Association- European Dialysis and Transplant Association, Amsterdam, Netherlands.

Goleg FA, Kong NCT, and Sahathevan R (2014). Dialysis-treated end-stage kidney disease in Libya: Epidemiology and risk factors. International Urology and Nephrology, 46(8): 15811587.

https://doi.org/10.1007/s11255-014-0694-1

PMid:24671275

Kerr M, Bray B, Medcalf J, O'Donoghue DJ, and Matthews B (2012). Estimating the financial cost of chronic kidney disease to the NHS in England. Nephrology Dialysis Transplantation, 27(suppl_3): iii73-iii80.

https://doi.org/10.1093/ndt/gfs269

PMid:22815543 PMCid:PMC3484716

Mathur AK, Ashby VB, Sands RL, and Wolfe RA (2010). Geographic variation in end-stage renal disease incidence and access to deceased donor kidney transplantation. American Journal of Transplantation, 10(4p2): 1069-1080.

https://doi.org/10.1111/j.1600-6143.2010.03043.x PMid:20420653

Nemati E, Ghanbarpour F, Taheri S, and Einollahi B (2008). Prevalence of hypertension among Iranian hemodialysis patients and associated risk factors: A nationwide multicenter study. Pakistan Journal of Biological Sciences, 11(6): 910-914. https://doi.org/10.3923/pjbs.2008.910.914 PMid:18814655

NIH (2020). Kidney disease statistics for the United States. National Institutes of Health: National Institute of Diabetes and Digestive and Kidney Diseases, Bethesda, USA.

Saeed AA, Al-Hamdan NA, Bahnassy AA, Abdalla AM, Abbas MA, and Abuzaid LZ (2011). Prevalence, awareness, treatment, and control of hypertension among Saudi adult population: A national survey. International Journal of Hypertension, 2011: 174135.

https://doi.org/10.4061/2011/174135

PMid:21912737 PMCid:PMC3168271

Saran R, Li Y, Robinson B, and Abbott KC (2016). US renal data system 2015 annual data report: Epidemiology of kidney disease in the United States. American Journal of Kidney Diseases, 67(3): A7-A8.

https://doi.org/10.1053/j.ajkd.2015.12.014

PMid:26925525 PMCid:PMC6643990

Saran R, Robinson B, Abbott KC (2020). US renal data system 2019 annual data report: Epidemiology of kidney disease in the United States. American Journal of Kidney Diseases, 75(1): A6A7.

https://doi.org/10.1053/j.ajkd.2019.09.003 PMid:31704083

SCOT (2018). Dialysis in the kingdom of Saudi Arabia. Saudi Center for Organ Transplantation: Saudi Journal of Kidney Diseases and Transplantation, 29(4):1012-1020. 
Sengul S, Erdem Y, Batuman V, and Erturk S (2013). Hypertension and chronic kidney disease in Turkey. Kidney International Supplements, 3(4): 308-311.

https://doi.org/10.1038/kisup.2013.64

PMid:25019009 PMCid:PMC4089601

Shaheen FA and Al-Khader AA (2005). Epidemiology and causes of end stage renal disease (ESRD). Saudi Journal of Kidney Diseases and Transplantation, 16(3): 277-281.
Tuttle KR, Bakris GL, Bilous RW, Chiang JL, De Boer IH, GoldsteinFuchs J, and Molitch ME (2014). Diabetic kidney disease: A report from an ADA Consensus Conference. American Journal of Kidney Diseases, 64(4): 510-533.

https://doi.org/10.1053/j.ajkd.2014.08.001 PMid:25257325 